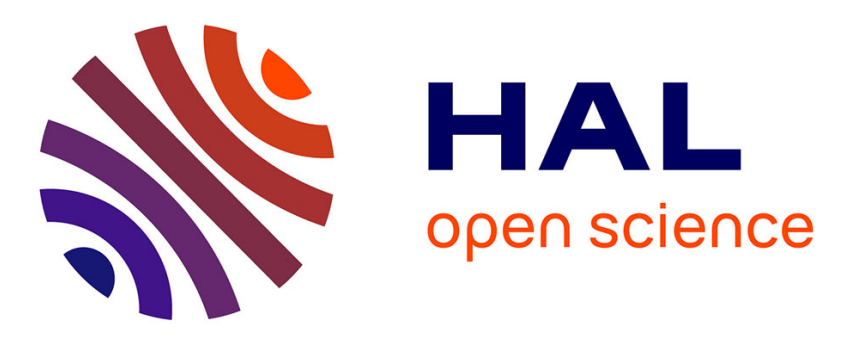

\title{
Melittin modifies bending elasticity in an unexpected way
}

Tanja Pott, Claire Gerbeaud, Nina Barbier, Philippe Méléard

\section{To cite this version:}

Tanja Pott, Claire Gerbeaud, Nina Barbier, Philippe Méléard. Melittin modifies bending elasticity in an unexpected way. Chemistry and Physics of Lipids, 2015, 185, pp.99-108. 10.1016/j.chemphyslip.2014.05.004 . hal-01019809

\section{HAL Id: hal-01019809 \\ https://hal.science/hal-01019809}

Submitted on 24 Sep 2014

HAL is a multi-disciplinary open access archive for the deposit and dissemination of scientific research documents, whether they are published or not. The documents may come from teaching and research institutions in France or abroad, or from public or private research centers.
L'archive ouverte pluridisciplinaire HAL, est destinée au dépôt et à la diffusion de documents scientifiques de niveau recherche, publiés ou non, émanant des établissements d'enseignement et de recherche français ou étrangers, des laboratoires publics ou privés. 


\section{Melittin modifies bending elasticity in an unexpected way}

Tanja Pott, Claire Gerbeaud, Nina Barbier and Philippe Méléard*

(a) Ecole Nationale Supérieure de Chimie de Rennes CNRS UMR 6226

11 allée de Beaulieu CS 50837

F-35708 Rennes Cedex 7, France

(b) Université Européenne de Bretagne

Corresponding author:

Philippe Méléard

ENSCR, 11 allée de Beaulieu CS 50837, F-35708 Rennes Cedex 7, France

Tel: +33223238078

Fax: +33223238199

Email: philippe.meleard@ensc-rennes.fr 


\section{Abstract}

Understanding the molecular mechanism of the interaction of amphipathic and antimicrobial peptides with membranes is of fundamental interest, especially because of the potential of amphipathic peptides as therapeutics. The most studied amphipathic peptides in this context are certainly melittin, magainin and alamethicin, of which melittin is the only one to exhibit a powerful hemolytic and therefore toxic action. Herein we study the effect of the antimicrobial but hemolytic peptide melittin on the bending elasticity of giant unilamellar vesicles (GUVs). The results are compared to the effects of nonhemolytic amphipathic peptides such as alamethicin. We found that monomeric melittin acts very differently on the membrane mechanical properties. Strikingly, the difference is the most pronounced for low peptide concentrations, relevant for the hemolytic action. This gives some insight into the subtle nature of this peptide-membrane interaction. Furthermore, the results show that bending elasticity measurements might be a sensitive way to distinguish between lytic and non-lytic antimicrobial peptides.

\section{Keywords}

Giant vesicles, melittin, bending elasticity, lysis, diacylglycerophosphatidylcholine, $x$-ray diffraction 


\section{Introduction}

Veterinary and medical practices of the last decades have lead to a druginduced selection of resistant and quite aggressive bacteria strains. This is partly responsible of a reinforced quest for molecules that could mimic antimicrobial compounds found in plants, insects, amphibians and mammals. One special class of such antimicrobial compounds are host defense peptides that come into play when infections or aggressions are detected (see for example (Bechinger, 2011) and references therein). These defense peptides act mainly on the cytoplasmic membranes of the cell target, leading to membrane permeabilization above a certain membrane concentration. This permeabilization happens via different mechanisms of peptide lipid association known as the detergent-like model, the carpet model and the wormhole or toroidal pore model (see for instance (Bechinger, 2009; Bechinger and Lohner, 2006)). More recently, even amyloid-type oligomerization of peptides was linked to membrane permeabilization (for some recent reviews see (Engel, 2009; Kagan, et al., 2012; Mahalka and Kinnunen, 2009)). .Anyhow, herein we focus on the pore-forming activity as a common mode of antimicrobial action of these peptides (Zasloff, 2002). Among these pore-forming amphipathic peptides are the non-hemolytic peptides magainin from the African clawed frogs Xenopus laevis (Bechinger, 1997; Ludtke, et al., 1996; Matsuzaki, 1998) as well as alamethicin produced by the fungus Trichoderma viride (see for example (Leitgeb, et al., 2007) and references therein). Both have been intensively studied and were shown to induce membrane thinning as a result of their absorption into the interfacial region of the membranes. Above a given critical fraction they then change their orientation into the membrane, leading to transmembrane pores (He, et al., 1996; Huang, 2006; Lee, et al., 2008; Ludtke, et al., 1996; Yang, et al., 2001). Another famous example of an amphipathic and pore forming peptide is melittin found in the venom of the European honey bee (Apis 
mellifera) (see for example (Raghuraman and Chattopadhyay, 2007) and references therein).

There has been an overwhelming number of studies on these peptides and others to find the molecular reasons responsible for their mechanisms of action. Many different characteristics have been explored in that respect, including their charge, their amphipathic feature, their secondary structure, the precise nature of the peptide-induced membrane perturbation or their possible auto-association within the model membrane in relation to transmembrane orientation and pore formation. Despite these numerous studies, some points remain, at least partly, unexplained. In the case of melittin, several similarities in the pore forming action compared to magainin or alamethicin have been found (Chen, et al., 2002; He, et al., 1996; Huang, 2006; Lee, et al., 2008; Ludtke, et al., 1996; Wu, et al., 1995; Yang, et al., 2001). Yet, only melittin has a strong hemolytic action and although there are some potential applications of melittin (Oršolić, 2012), this cytotoxic feature makes melittin rather worthless as an antibiotic.

Bending elasticity is the mechanical parameter that characterizes the membrane resistance to local curvature changes induced by external stresses as small as Brownian motion. It is strongly dependent on subtle modifications of the environment characteristics like a pH shift (Méléard, et al., 1998; Mitkova, et al., 2014), a change in temperature (Fernandez-Puente, et al., 1994; Méléard, et al., 1997) or aqueous salinity, the chosen buffer and its concentrations (Méléard, et al., 1998). Naturally, bending elasticity is influenced by the lipid composition of the bilayer (Fernandez-Puente, et al., 1994; Méléard, et al., 1997), sometimes simply related to the hydrophobic thickness (Fernandez-Puente, et al., 1994), sometimes in a more unexpected manner as shown in the case of photo-induced lipid peroxidation (Bouvrais, et al., 2010; Méléard, et al., 2011). In the context of peptide-lipid interactions, we also showed that the amphipathic peptides 
magainin 2 and alamethicin strongly decrease bending elasticity (Bouvrais, et al., 2008; Vitkova, et al., 2006).

In the following, we will focus on the influence of melittin on the bending elasticity. Actually, the hemolytic activity of melittin constitutes its principal biological action (Castano, et al., 1999; DeGrado, et al., 1981; Habermann, 1972; Tosteson, et al., 1985). Melittin-induced hemolysis happens within seconds at submicromolar concentrations and it has been shown that the binding of melittin to red blood cells as a monomer species is necessary for this hemolytic activity (Hider, et al., 1983). Accordingly, we chose to work with monomeric melittin only. After a partition coefficient study of melittin in our peculiar environmental conditions and a verification of melittin-induced membrane thinning, the bending elasticity results will be compared notably to alamethicin, but also to magainin.

In this context, one may treat amphipathic and $\alpha$-helical peptides such as melittin, magainin 2 and alamethicin as rather simple inclusions that adsorb on a membrane leading at intermediate concentration to bilayer thinning. At high concentration, these peptides adopt transmembrane orientation and become pore-forming, with alamethicin arranging as a barrel stave pore, whereas magainin and melittin pores are consistent with toroidal (or wormhole) pores (Bechinger, 1997; Bechinger, 2009; He, et al., 1996; Huang, 2006; Lee, et al., 2008; Yang, et al., 2001). However, differences in the detailed behavior should nevertheless be expected, particularly when taking into account peptide induced local curvature as well as direct interactions between peptides within the same monolayer or across the bilayer as in the model presented in (Bouvrais, et al., 2008). We will show that melittin has a very different effect on membrane elasticity compared to alamethicin (Vitkova, et al., 2006) or magainin (Bouvrais, et al., 2008). This is somewhat unexpected but may constitute a key finding in the context of melittin lytic and hemolytic action. 


\section{Materials and methods}

\subsection{Materials}

Stearoyl-oleoyl phosphatidylcholine, SOPC, was obtained from Avanti Polar Lipids Inc. (Birmingham, AL). Highly purified melittin was purchased from Serva (Heidelberg, Germany) and used without further purification. NBD-PE (N-(7-nitrobenz-2-oxa-1,3-diazol-4-yl)-1,2-dihexadecanoyl-sn-glycero-3phosphoethanolamine triethylammonium salt), ANTS (8aminonaphthalene-1,3,6-trisulfonic acid, disodium salt) and DPX (p-xylene-bispyridinium bromide) were purchased from Molecular Probes Inc (OR). NATA (N-acetyl triptophanamide) was from Sigma-Aldrich Chimie (France) and nonionic surfactant $\mathrm{C}_{14} \mathrm{E}_{6}$ from Nikko Chemicals (Japan).

\subsection{Sample preparations}

To ensure the presence of monomeric melittin in GUV experiments and the partition study, buffers at 1 to $10 \mathrm{mmol} / \mathrm{L}$ Tris (Trizma Base, Sigma-Aldrich Chimie, France) adjusted to $\mathrm{pH} 7.4$ and containing 0.2 to $2 \mathrm{mmol} / \mathrm{L}$ EDTA (ethylenediaminetetraacetic acid, Sigma-Aldrich Chimie, France) were used.

Giant Unilamellar Vesicles (GUVs) were obtained by electroformation under standard "low salt" conditions as described elsewhere (Méléard, et al., 2009; Pott, et al., 2008). One has to note first that the inner walls of the electroformation cell were incubated with the studied peptide solution as it is well known that basic peptide like melittin strongly adsorbs onto the freshly cleaned glass. Further, for very high peptide concentrations ( $\geq 10 \mathrm{mmol} / \mathrm{l})$, we had to co-dissolve melittin and SOPC into the chloroform/methanol solution to be able to obtain giant vesicles.

Large unilamellar vesicles (LUVs) with a diameter of $0.2 \mu \mathrm{m}$ were obtained by extrusion according to standard procedures and used freshly. For 
FRET experiments, SOPC was enriched with NBD-PE at 0.3 mol\%. Lipid concentration was obtained by absorption measurements (Lambda 35, PerkinElmer, France) using small unilamellar vesicles (SUV) obtained by sonication and containing $0.3 \mathrm{~mol} \%$ of NBD-PE lipid (the lipid mixture was provided by the stock solution we used for FRET experiments). The melittin concentration of the stock solution was determined using tryptophan adsorption with a molar extinction coefficient $\varepsilon_{280}^{\text {mel }}$ equal to $5570 \mathrm{~mol}^{-1} \mathrm{~cm}^{-1}$ (Dufourcq, et al., 1986).

Oriented samples for x-ray diffraction studies were prepared on curved glass substrates using a method adapted from (Franks and Lieb, 1979; Jacobs and White, 1989; Wiener and White, 1991). Contrariwise to standard preparations of oriented bilayer samples, we did not use any organic solvent but used aqueous vesicle dispersions as a precaution to not perturb melittin incorporation into the membrane by a co-solubilization process. This is especially important for melittin as it has also been pointed out that the way the oriented samples are prepared might influence the peptide orientation (Smith, et al., 1994). Vesicle dispersions were prepared in excess water and freezethawed several times. In the case of melittin containing samples, the peptide was further incubated with the vesicles and for high peptide-to-lipid molar ratios, $\mathrm{P} / \mathrm{L}$, the well-known melittin-induced morphological transition from MLVs to smaller objects (Dempsey, 1990; Dufourcq, et al., 1986) was detected by optical clearance of the sample. Oriented membranes were prepared by applying some $\mu \mathrm{L}$ of the vesicle dispersion on the curved substrate and dried at room temperature and humidity. The process was repeated until the sample contained about 1-2 mg of phospholipids. The sample was placed in a homemade sample holder. The relative humidity, $\mathrm{RH}$, inside the sample holder was controlled by saturated salt solutions and the temperature was controlled to be $25 \pm 0.5^{\circ} \mathrm{C}$. It should also be noted that such a standard humidity chamber does not allow full lipid multilayer hydration even not at $100 \% \mathrm{RH}$, but always 
stays somewhat lower. This is also called the vapor pressure paradox (Nagle and Katsaras, 1999). Samples were allowed to equilibrate for several hours prior acquisition of x-ray diffractions and considered to be in equilibrium when consecutive diffraction patterns remained unchanged.

\subsection{Vesicle fluctuation analysis}

Direct GUV observations were made using an inverted microscope (Axiovert 135, Zeiss, Germany), equipped with a $\times 63$ objective for phase contrast. We used a CCD video camera (C5985, Hamamatsu, Japan) connected to a computer for image capture and analysis. The detailed method for measuring bending elasticity from the observation of thermal fluctuations of GUV membranes was already detailed in the past (see for example (Méléard, et al., 1997)).

\subsection{FRET experiments}

Fluorescence measurements were obtained using a Fluoromax 3 (Jobin YvonHoriba, France). The excitation wavelength was $\lambda_{e x c}=290 \mathrm{~nm}$, i.e., close to the melittin absorption maximum, the emission being recorded at $\lambda_{e m}=532 \mathrm{~nm}$ for energy transfer detection from NBD-PE probes. An UV-filter was introduced between the cell and the emission slits to exclude any contribution originating from the excitation monochromator (second mode diffraction).

The partitioning coefficient of melittin between SOPC bilayers and the buffer was determined using $3 \mathrm{ml}$ buffer solution at a given lipid concentration, $L$, varying from about 15 to $210 \mu \mathrm{mol} / \mathrm{L}$. Using a motorized injector (Fisher Bioblock Scientific) melittin was added to a given LUV dispersion in a continuous manner using injections rates (from $15 \mu \mathrm{l} / \mathrm{h}$ to $100 \mu \mathrm{l} / \mathrm{h}$ ) known to be slow enough to allow equilibration, or more precisely, known to lead to injection rate independent behaviors for phospholipid-melittin systems (Pott, et al., 1998). The measured fluorescence intensity as a function of total peptide 
concentration, $P$, corrected for background and slits using a NATA reference solution, was then directly related to the amount of melittin absorbed on the LUVs.

\subsection{Lysis experiments}

Lysis experiments were done with LUVs obtained by extrusion according to a standard protocol. SOPC LUVs were prepared in $9 \mathrm{mmol} / \mathrm{L}$ ANTS, $15 \mathrm{mmol} / \mathrm{L}$ DPX, $10 \mathrm{mmol} / \mathrm{L}$ Tris and $2 \mathrm{mmol} / \mathrm{L}$ EDTA. Exclusion chromatography was used to exchange outside vesicle environment with $10 \mathrm{mmol} / \mathrm{L}$ Tris, $2 \mathrm{mmol} / \mathrm{L}$ EDTA where $40 \mathrm{mmol} / \mathrm{L} \mathrm{NaCl}$ was added for iso-osmolarity (osmolarity of external and internal buffers was measured and found to be $100 \mathrm{mOsmol} / \mathrm{kg}$ ). This buffer is of somewhat higher ionic strength than those used in the GUV and FRET experiments. However, final peptide concentrations during lysis experiments never exceeded $0.2 \mu \mathrm{mol} / \mathrm{L}$. These very low peptide concentrations combined with the used buffer warrant conditions where melittin is monomeric in solution (Faucon, et al., 1979; Talbot, et al., 1982; Talbot, et al., 1979). The lipid concentration of LUV suspension after exclusion chromatography was found to be $0.8 \mathrm{mmol} / \mathrm{L}$. $40 \mu \mathrm{L}$ of that suspension completed to $2 \mathrm{~mL}$ with the external buffer was added in a quartz cuvette, leading to a lipid concentration for lysis experiments equal to $16 \mu \mathrm{mol} / \mathrm{L}$. The aqueous melittin solutions used in this experiment $(0,31 \mu \mathrm{mol} / \mathrm{L}, 3.11 \mu \mathrm{mol} / \mathrm{L}$ and $31.10 \mu \mathrm{mol} / \mathrm{L}$ ) were chosen depending on the studied final peptide concentration to limit dilution. At the end of each experiment, $\mathrm{C}_{14} \mathrm{E}_{6}$ surfactant solution was added to normalize each measurement towards $100 \%$ lysis. Each experimental point corresponds to 2 independent measurements. 


\subsection{X-ray measurements and analysis}

Small angle $x$-ray scattering (SAXS) experiments were carried out in the laboratory using a rotating $\mathrm{Cu}$ anode $\mathrm{x}$-ray generator (Bruker Nonius FR59) equipped with a 2D reflection system (Montel 200 multilayer graded optic), used as a monochromator and collimator (Ka wavelength $\lambda=1.54187 \AA$ ). Three sets of vertical and horizontal slits were used, leading to a spot size of $0.5 \mathrm{~mm} \times 0.5 \mathrm{~mm}$. A 2D Marresearch imaging plate detector (mar345dtb) with a plate diameter of $345 \mathrm{~mm}$ and a pixel size of $150 \mu \mathrm{m} \times 150 \mu \mathrm{m}$ was used to collect the data. The spot size, defined by three sets of vertical and horizontal slits, was approximately $1 \mathrm{~mm} \times 1 \mathrm{~mm}$. Diffraction patterns consisted of 6 to 8 (4 to 6 for melittin containing samples) discernible Bragg peaks with a mosaic spread for all samples between $1^{\circ}$ and $3^{\circ}$. Diffractions were corrected for the sample geometry (curved substrate), absorption, polarization and mosaicity similar to (Wiener and White, 1991). Peak positions and intensities were then accurately determined by Gaussian fits. Intensities were then further corrected for the Lorentz factor.To reconstruct $1 \mathrm{D}$ electron density profiles, EDP, the swelling method was used for the determination of the relative phases of Bragg reflection (Franks and Lieb, 1979) and intensities were scaled to satisfy Blaurock's scaling relation (Blaurock, 1971)

$$
\sum_{h}\left|F\left(\frac{2 \pi h}{d}\right)\right|^{2}=\frac{d}{d_{0}}
$$

where $d_{0}$ is a constant (an arbitrarily chosen value of the repeat distance $d$ ) for the swelling series. Amplitudes, i.e., the square root of the scaled intensities $(F(h)=\sqrt{I(h)})$, were plotted as a function of the reciprocal lattice vector $(q=4 \pi \sin \theta / \lambda)$. The phases of the centrosymmetrical bilayer were chosen so that the data points fell on a single smooth curve. Alternative phase assignments for higher orders were considered and rejected as they produced electron density profiles that were physically implausible. 
With phases determined, the relative scattering amplitudes were Fouriertransformed to obtain the scattering density profile (relative electron density profile), @sc. This profile was related to the true electron density by $\rho=c \rho_{S C}+b$, the constant $b$ being introduced because the zero-order scattering amplitude is not measurable.

Area per SOPC lipid was determined using a method first developed by (McIntosh and Simon, 1986) for DLPE and later adapted for DPPC (Nagle, et al., 1996) and DOPC (Tristram-Nagle, et al., 1998).

\section{Results}

Stearoyl-oleoyl phosphatidylcholine, SOPC, is particularly suited for GUV electroformation and was therefore chosen as an overall neutral phospholipid. SOPC is actually zwitterionic bearing a very weak negative overall charge when organized in a bilayer (Pincet, et al., 1999). Buffer conditions were chosen to be of low ionic strength in order to avoid the well-known monomer-to-tetramer transition of melittin (Talbot, et al., 1979). Under these conditions, aqueous melittin is monomeric even at $40 \mu \mathrm{mol} / \mathrm{L}$ (Quay and Condie, 1983), i.e., the highest concentration used herein.

Fig. 1A shows the evolution of membrane bending elasticity, $k_{c}$, as a function of total melittin concentration in the observation chamber. For comparison, melittin-induced lysis on SOPC LUVs is shown in Fig. 1B. As can be seen, peptide concentrations investigated for bending elasticity measurements are much higher, i.e., from 0.4 to $40 \mu \mathrm{mol} / \mathrm{L}$, than those necessary to induce complete lysis, i.e., about $0.04 \mu \mathrm{mol} / \mathrm{L}$. This is important, inasmuch as GUV electroformation was done in the presence of aqueous peptide solution, melittin may be incorporated into the GUV membrane in an asymmetric manner. Anyhow, at peptide concentration much higher than those 
needed for complete lysis, it can safely be assumed that the membrane bound peptide is distributed symmetrically since melittin is known to translocate across the membrane during lysis (Matsuzaki, et al., 1997).

Membrane bending elasticity, $k_{c}$, decreases progressively with increasing melittin concentration. Similar peptide-induced $k_{c}$ decreases have already been reported for the DPhPC-alamethicin system (direct measurements (Vitkova, et al., 2006)), DOPC and diC22:1PC-alamethicin systems (indirect measurements (Pabst, et al., 2007; Pan, et al., 2009)) as well as for POPC-magainin 2 (direct measurements (Bouvrais, et al., 2008). As lipid concentrations used in the latter studies were comparable to the ones used herein, we can compare more quantitatively the bilayer softening induced by the three peptides. In order to decrease $k_{c}$ by a factor of two, one needs approximately $6 \mu \mathrm{mol} / \mathrm{L}$ melittin, about $1.5 \mu \mathrm{mol} / \mathrm{L}$ alamethicin (Vitkova, et al., 2006) and about $0.4 \mathrm{~mol} / \mathrm{L}$ magainin (Bouvrais, et al., 2008). That melittin was found to be the least efficient peptide in reducing $k_{c}$ was somewhat surprising, because melittin was known to be the most efficient ones in respect to lysis (Dathe and Wieprecht, 1999). In this context, it might be worthwhile to recall that melittin shows indeed a strong lytic action on SOPC LUVs (Fig 1B) far below the micromolar concentration used for $k_{c}$ measurements.

However, for correct comparison, the decrease in $k_{c}$ should be expressed as a function of the bound peptide-to-lipid molar ratio, $P^{b} / L$, because at low $P^{b} /$ $L$, the bilayer is obviously not heavily charged and the adsorption process is strongly favorable, whereas at higher $P^{b} / L$, the bilayer charge is becoming larger and one has to strongly increase the free peptide concentration to induce more adsorption. Partition coefficients, $K_{p}$, have already been reported in the literature. In the case of phosphatidylcholine lipids and alamethicin, a $K_{p}$ of $1.3 \times 10^{3} \mathrm{~L} / \mathrm{mol}$ has been reported (Schwarz, et al., 1986) while for the POPCmagainin system, $K_{p}$ is about $2000 \mathrm{~L} / \mathrm{mol}$ (Wieprecht, et al., 1999). For melittin, 
$K_{p}$ values have been shown to vary strongly as a function of the lipid, i.e., $K_{p}=2 \times 10^{3}, 2.4 \times 10^{4}$ and $2.53 \times 10^{5} \mathrm{~L} / \mathrm{mol}$ for POPC, DOPC and eggPC (Torrens, et al., 2007), and as a function of the ionic strength (Rex and Schwarz, 1998; Schwarz and Beschiaschvili, 1989). Therefore, we chose to measure $K_{p}$ for SOPC-melittin system at the same low ionic strength used for the bending elasticity measurements, by means of FRET between the melittin tryptophan and DNS-labeled LUVs.

The insert of Fig. 2 shows a typical FRET experiment. For very low $P$, fluorescence intensity increases almost linearly, showing that peptide binding is efficient. For higher $P$, the melittin binding rate decreases progressively as expected. Since the absolute amount of FRET intensity $\Phi$ is, via the DNS-labeled lipid, directly related to the amount of SOPC, $\Phi$ should be divided by lipid concentration, $L$, in order to compare experiments conducted at different $L$. $\Phi / L$ was then proportional to $P^{b} / L$, meaning that a given $\Phi / L$ corresponded to a given $P^{b} / L$ characterized by a defined total peptide concentration, $P$, at a given lipid concentration, $L$. Indeed, the total peptide concentration, $P$, needed to attain a given $\Phi / L$ will be higher for higher lipid concentration, L. Fig. 2 shows these results and the corresponding linear relation between $P$ and $L$ at a given $\Phi / L$ (i.e., a given $P^{b} / L$ ) that can be expressed by (Ollivon, et al., 1988; Paternostre, et al., 1988; Pott, et al., 1998):

$$
P=P^{f}+\left(P^{b} / L\right) \times L
$$

The slope of such a linear fit yields $P^{b} / L$ and the intercept extrapolation the free or unbound peptide, $P f$, Fig. 2. Collecting the data over the melittin range suitable for the fluorescent detection limit, we got Fig. 3 linking $P^{f}$ and $P^{b} / L$ or equivalently, the effective partition coefficient, $K_{p}^{e f f}=\left(P^{b} / L\right) / P^{f}$.

As a consequence of the high melittin concentrations needed to induce a rather important decrease in bending elasticity, it was necessary to extrapolate $P$ and $P^{f}$ values obtained from FRET experiments to the conditions used for GUV 
experiments (average lipid concentration of about $8 \mu \mathrm{mol} / \mathrm{L}$ and melittin concentration up to $40 \mu \mathrm{mol} / \mathrm{L}$ ) by interpreting our data in terms of partitioning equilibrium. As mentioned above, such an approach has already been published before for charged peptides (Kuchinka and Seelig, 1989; Rex and Schwarz, 1998; Schwarz and Beschiaschvili, 1989; Wieprecht, et al., 1999). They are generally solving the increasing charge of the membrane induced by the peptide adsorption as a classical Gouy-Chapman problem, associated to simple partition equilibrium. It has been concluded, as expected, that charged peptides have a decreasing affinity for the membrane when the bilayer charge increases. This can indeed be concluded from Fig. 3. Such a behavior can be understood using the theoretical equations published in (Kuchinka and Seelig, 1989; Rex and Schwarz, 1998; Schwarz and Beschiaschvili, 1989; Wieprecht, et al., 1999), assuming a symmetric electrolyte:

$$
P^{f}=\frac{P^{b}}{L} \times \frac{1}{K_{P}}\left[\frac{v b}{L / P^{b}+a_{P} / a_{L}}+\sqrt{1+\left(\frac{v b}{L / P^{b}+a_{P} / a_{L}}\right)^{2}}\right]^{2 v}
$$

where $K_{P}$ is the membrane partition coefficient connecting bound peptide, $P^{b}$, and buffer peptide concentration, $P f$, in the membrane vicinity (Kuchinka and Seelig, 1989). $v$ is the peptide charge on the membrane that is generally found to be smaller than the corresponding peptide charge in water, and $a_{P} / a_{L}$ is the peptide surface divided by the lipid surface. According to literature, $b=e /\left(a_{L} \sqrt{8000 R T \varepsilon_{0} \varepsilon_{r}[\text { salt }]}\right) \sim 2.17 / \sqrt{[\text { salt }]}$ is the variable taking into account the buffer concentration of a symmetric monovalent salt (Kuchinka and Seelig, 1989; Rex and Schwarz, 1998; Schwarz and Beschiaschvili, 1989; Wieprecht, et al., 1999). In our case, $b$ was difficult to estimate accurately because our buffer was a mixture of ions with different valences (Tris buffer containing EDTA). However, it can be noted that the ratio $a_{P} / a_{L}$ might be considered as small enough to be neglected with respect to $L / P^{b}$ in our FRET and GUV experiments. 
Consequently, a simplified expression was used to describe the behavior seen in Fig. 3 (Schwarz and Beschiaschvili, 1989):

$$
P^{f}=\frac{P^{b}}{L} \times \frac{1}{K_{P}}\left[\beta \frac{P^{b}}{L}+\sqrt{1+\left(\beta \frac{P^{b}}{L}\right)^{2}}\right]^{2 v}
$$

$\beta$ being theoretically equal to $v b$. The experimental data shown in Fig. 3 were fitted according to the above equation, seeking for the peptide charge $v$, the salinity parameter $\beta$ and the membrane partition coefficient $K_{P}$. We found $K_{P}=4.7 \times 10^{6} \mathrm{~L} / \mathrm{mol}, v=3.1$ and $\beta=97$. Further, using Fig. 3 and the obtained fitting parameters, it is straightforward to deduce $K_{p}^{\text {eff }}=P^{b} /\left(P^{f} \cdot L\right)$ in different experimental conditions.

Bending elasticity is known to be related to membrane characteristics such as lipid area, bilayer thickness and stretching elasticity (Petrov and Bivas, 1984; Szleifer, et al., 1990). Consequently, bending elasticity variation as a function of bound peptides may be related to a change in the membrane thickness that could be induced by peptide adsorption as was invoked and shown for example in the case of magainin, melittin or alamethicin (Chen, et al., 2002, 2003; Li and Salditt, 2006). This is the reason why we were interested by xray measurements, or more precisely, by the determination of the scattering density profile, @sc. Fig. 4 shows a part of the results used to get @sc as a function of bound melittin. Fig. 4A shows the reduction of the bilayer repeat distance of oriented SOPC bilayers when changing the sample humidity and the associated changes of the relative intensity of the main peaks that can be used to solve the phase problem. Then, the obtained phase diagrams like those shown in Fig. 4B for pure SOPC and melittin SOPC mixture at $P / L \approx P b / L=1: 70$ studied at different humidities were used to determine the electron density profiles of melittin SOPC mixtures at different $P / L$. Fig. $4 \mathrm{C}$, shows the electron density profiles obtained for the melittin-SOPC system at $100 \% \mathrm{RH}$, which 
actually means that the system is somewhat less hydrated than what would be expected at full hydration, also know as the vapor pressure paradox (Nagle and Katsaras, 1999). However, there is only a small influence of the melittin content on the peak-to-peak distance $\left(d_{P P}\right)$ comparable to what has already been published in the case of the melittin-POPC or DOPC systems (Huang, 2006; Lee, et al., 2004; Yang, et al., 2001).

\section{Discussion}

In the previous section, we showed that monomeric melittin induces an important reduction in bending elasticity only for concentrations far above those necessary to induce lysis. In the case of melittin, lysis is initiated very rapidly, followed by translocation across the membrane (Matsuzaki, 1998; Raghuraman and Chattopadhyay, 2007). Accordingly, one can safely assume that melittin is distributed symmetrically across the GUV bilayers. This argument also holds for the FRET experiments. Indeed, membrane budding induced by minute bilayer spontaneous curvature that would indicate an asymmetric distribution were never observed. Also, throughout our study, we used buffer systems of very low ionic strength to inhibit melittin tetramerization in solution. The effective partition coefficient $K_{p}^{e f f}=P^{b} /\left(P^{f} \cdot L\right)$ under these conditions is for example $K_{p}^{\text {eff }} \sim 1.6 \times 10^{6} \mathrm{~L} / \mathrm{mol}$ at $P=0.4 \mu \mathrm{mol} / \mathrm{L}$ while $K_{p}^{\text {eff }} \sim 9.5 \times 10^{4} \mathrm{~L} / \mathrm{mol}$ at $P=10 \mu \mathrm{mol} / \mathrm{L}$ and $K_{p}^{\text {eff }} \sim 3 \times 10^{4} \mathrm{~L} / \mathrm{mol}$ at $P=40 \mu \mathrm{mol} / \mathrm{L}$. The two latter values are lower than that obtained by Allende and collaborators (Allende, et al., 2003). This is not unexpected as Allende and coworkers used a buffer with a higher salt concentration, where melittin tetramerization is not inhibited. The deduced peptide charge $(v=3.1)$ we found is a bit stronger compared to what has been reported by others (Rex and Schwarz, 1998; Schwarz and Beschiaschvili, 1989). Anyhow, one may expect the effective peptide charge to increase at reduced ionic strength. $\beta$ may be used to 
determine the apparent ionic strength. We found $b=\beta / v \approx 2.17 / \sqrt{[\text { salt }]}$ giving [salt $] \approx 5 \mathrm{mmol} / \mathrm{L}$ where an estimation of the ionic strength with our buffer was found to be $5.9 \mathrm{mmol} / \mathrm{L}$, which is indeed much lower than the $110 \mathrm{mmol} / \mathrm{L}$ used by Rex and Schwarz (Rex and Schwarz, 1998).

Fig. 5A shows bending elasticity values, $k_{c}$, as a function of bound melittin to lipid ratio, $P^{b} / L$, divided by bending elasticity of pure lipid bilayers in the same buffer, $k_{c}^{L}$, using results shown in Fig. 1A and the partition studies, Fig. 3. It is interesting to compare this data to other well characterized systems, such as DLPC-alamethicin, (Vitkova, et al., 2006)(He, Ludke Huang 1995 Biochemistry), DPhPC-alamethcine (Vitkova, et al., 2006) (Chen, et al., 2003; Wu, et al., 1995), DOPC-alamethcin (Huang, et al., 2004; Pabst, et al., 2007; Pan, et al., 2009) or POPC magainin (Bouvrais, et al., 2008; He, et al., 1996). All these systems show similar decreases in bending elasticity with increasing peptide-tolipid ratio, despite the fact that they form different types of membrane pores and insert in a transmembrane manner at quite different concentrations. Yet, for the SOPC-melittin system the shape of the bending elasticity reduction is somewhat unexpected. To illustrate this point, we added the already published results of the diphytanoyl phosphatidylchloline (DPhPC) alamethicin system (Vitkova, et al., 2006) using the same relative change in bending elasticity, $k_{c} /$ $k_{c}^{L}$, as a function of $P^{b} / L$. It can clearly be seen that melittin and alamethicin have very different effects on bending elasticity of SOPC and DPhPC bilayers, respectively. In the case of the SOPC-melittin system, bending elasticity is poorly influenced by bound melittin at $P^{b} / L$ up to 0.01 but it should be noted that the observed small decrease is significant anyway. For higher $P b / L$, the decrease is much more pronounced, indicating some kind of synergy in the action of melittin on bilayer bending stiffness as the fraction of membrane inserted peptide becomes higher. This behavior is in contrast to the DPhPC alamethicin system. For the latter, bending elasticity decreases rapidly at small 
$P^{b} / L$. At larger $P^{b} / L$, this effect calms down and reaches saturation like state, comparable to what has been found in the case of POPC magainin systems (Bouvrais, et al., 2008).

These very different effects of melittin and alamethicin on bending elasticity stiffness, a property characterizing the mesoscopic scale, may be in relation to the precise way the peptides perturb the bilayer at the molecular scale. Fig. 5B shows the corresponding monolayer thinning caused upon adsorption of melittin and alamethicin as a function of $P^{b} / L(P / L)$. The data for the SOPC/melittin was obtained by measuring the peak-to-peak distance $\left(d_{P P}=2 \times l_{h}\right)$ from electron density profiles obtained herein. In the case of the alamethicin DPhPC system we used published valued from (Wu, et al., 1995). Melittin and alamethicin both decrease the monolayer thickness in the very same way up to $P / L \approx P b / L$ of about 0.07 . Above this value, melittin did not influence the SOPC monolayer thickness in a sensitive way. Such saturation was already seen in the case of DOPC melittin system at a similar $P / L$ and was attributed to a transition from S-to-I state in the case of amphipathic peptides (Chen, et al., 2003). The "surface" S-state corresponds to peptides that are oriented parallel to the plane of the membrane, cause membrane thinning and do not form pores. The "inserted" I-state corresponds to peptides oriented perpendicular to the membrane plane, that form non-transient pores, whereas the bilayer thickness remains constant. In the explored bound peptide range, alamethicin follows its previous influence at the same rate (alamethicin in DPhPC adsorbs on the bilayer, i.e., its $\alpha$-helix long axis is perpendicular to the membrane normal, up to $P / L=1 / 60-1 / 40$ (Chen, et al., 2003; Wu, et al., 1995)). Comparing the bending elasticity reduction, Fig. 5A, and the membrane thinning effect, Fig. 5B, we concluded that the main influence on bending elasticity caused by alamethicin corresponds to membrane bound peptide concentrations that result in significant membrane thinning. Contrastingly, 
melittin absorption on SOPC bilayers does result in membrane thinning but in a range of $P / L$ where $k_{c}$ is hardly perturbed. At higher $P / L$ when the membrane thickness stays constant, $k_{c}$ decreases finally. While changes in bending elasticity are often cited as being mainly influenced by bilayer thickness or other membrane characteristics (Allende, et al., 2005), the effect of melittin on SOPC bilayers is clearly not related to its thinning effect.

However, above $P^{b} / L=1 / 100$, bending elasticity as a function of melittin adsorption drops swiftly, indicating some kind of cooperative behavior that may lead to membrane destabilization. In fact, extrapolating bending elasticity in Fig. 5A to high $P^{b} / L$, leads to cancellation of bilayer bending elasticity close to $P^{b} / L \approx 1 / 50$. Such a cooperative effect has to be related to interactions between melittin molecules within the same monolayer or across the bilayer. Attractive or repulsive interactions may be directly generated by the peptide inclusions and, more probably, via the perturbations induced by peptide inclusions onto the lipid matrix. This was essentially the interpretation made in (Bouvrais, et al., 2008) to explain the softening effect of magainin upon adsorption onto POPC bilayers. Introducing $\rho_{0}$ as the mean peptide density in the membrane, $\lambda$ as the coupling between membrane curvature and compositional asymmetry of the peptide distribution, $t$ and $s$ as the parameters describing intramonolayer an intermonolayer peptide interactions respectively, one gets (Bouvrais, et al., 2008):

$$
k_{c}^{e f f}=k_{c}-\frac{4 \lambda^{2} \rho_{0} / k_{B} T}{1+(t-s) \rho_{0} / k_{B} T}
$$

This relation predicts a reduction of the effective bending elasticity of a membrane containing peptides, $k_{c}^{\text {eff }}$, with respect to that of pure lipid bilayer, $k_{c}$. For low mean peptide densities, $\rho_{0}$, this model predicts a linear decrease of bending elasticity similar to an earlier interpretation (Leibler, 1986). At higher $\rho_{0}$ however, this reduction is slowing down and eventually saturates if $(t-s)$ is 
positive while it accelerates when $(t-s)$ is negative (Bouvrais, et al., 2008). One should note that this model treats the peptide as a simple inclusion and yields information about peptide induced local curvature and the interaction of peptides across the bilayer. It does not account for a detailed information about the exact orientation of the peptide within the membrane or for transitions from $S$ to I states. As such, the model is rather robust and not very sensitive to the exact peptide area. Comparing the melittin-induced reduction in $k_{c} / k_{c}^{L}$ to alamethicin, Fig. 5A, reveals very clearly these two different effects: (i) high activity at low peptide concentration followed by a saturation for the DPhPCalamethicin system as already found for POPC-magainin-2 (Bouvrais, et al., 2008) and (ii) low activity at low melittin concentration and destabilization for high melittin content of SOPC bilayers.

To analyze these behaviors in greater details, we introduce the relation between $P^{b} / L$ and $\rho_{0}$ :

$$
\rho_{0}=\frac{P^{b} / L}{A_{L}+A_{P} \cdot P^{b} / L}
$$

where $A_{L}$ and $A_{P}$ are lipid and peptide surface areas respectively. Expressing $A C_{P}$ as the peptide area coverage fraction as in (Bouvrais, et al., 2008) leads to:

$$
A C_{P}=\frac{A_{P} \cdot P^{b} / L}{A_{L}+A_{P} \cdot P^{b} / L}
$$

The peptide and lipid areas can be obtained from $\mathrm{x}$-ray data analysis $(\mathrm{Wu}$, et al., 1995). In the case of the DPhPC alamethicin systems, we used $A_{\mathrm{DPhPC}}=76 \AA^{2}$ and $A_{\mathrm{Ala}}=280 \AA^{2}$ (or $A_{\mathrm{Ala}}=350 \AA^{2}$ from standard values of $\alpha$-helix dimensions) as published by (Wu, et al., 1995). Following the same approach for melittin SOPC mixtures, we obtained $A_{\mathrm{Mel}}=190 \AA^{2}$ from the initial linear decrease of membrane thickness with increasing peptide concentration (Fig. 5B). The physical cross section of melittin can also be estimated to be about $400 \AA^{2}$. Actually, the S-state peptide area $A_{\mathrm{P}}$ is always less than the physical cross 
section of the peptide molecules (Lee, et al., 2004; Lee, et al., 2005). A convincing interpretation of this phenomenon has been provided by (Heller, et al., 1997; Huang, 2006; Lee, et al., 2004). According to the authors, the binding of a peptide to a bilayer triggers the release of water molecules from the interfacial region. The lipid area of our lipid was also determined from our data and found to be $A$ SOPC $=64.1 \AA^{2}\left(25^{\circ} \mathrm{C}\right)$, a value that compares well to the $63.8 \AA^{2}\left(30^{\circ} \mathrm{C}\right)$ reported by (Kučerka, et al., 2011), or $66 \AA^{2}\left(30^{\circ} \mathrm{C}\right)$ by (Rand, et al., 1988).

Figure 6 shows the reduction in bending elasticity as a function of peptide area coverage, $A C_{P}$, for the alamethicin-DPhPC and melittin-SOPC systems. The rapid decrease of bending stiffness at low alamethicin concentrations is even more striking using this peptide area coverage representation. One may further notice that the predicted saturation point for the bending elasticity of alamethicin-DPhPC mixtures has seemingly not been reached. Indeed, the critical concentration for insertion of alamethicin into DPhPC bilayers has not been attained (Chen, et al., 2003; Wu, et al., 1995) and it may be suspected that the reduction in $k_{c}$ levels out when approaching insertion. However, using $A_{\mathrm{Ala}}=280 \AA^{2}$ and $A_{\mathrm{DPhPC}}=76 \AA^{2}$, the coupling parameter $\lambda$ obtained from Eqs. (3) and (4) was found to be equal to $(2.53 \pm 0.16)$ $\mathrm{x} 10^{-28} \mathrm{Jm}$. This value is smaller but comparable to the $(3.19 \pm 0.37) \times 10^{-28} \mathrm{Jm}$ found for magainin-POPC system (Bouvrais, et al., 2008). The coupling parameter $\lambda$ corresponds actually to a peptide-induced local curvature that is rather high for alamethicin. This reveals that alamethicin behaves very much like magainin, leading to local patches of rather high-curvature. As stated before, the saturation-like behavior is predicted to be associated to a positive $(t-s)$ value, describing larger peptide interactions within the same monolayer ( $t$ parameter) with respect to inter-monolayer peptide interactions (s parameter). We found $(t-s)=(2.65 \pm 0.40) \times 10^{-36} \mathrm{Jm}^{2}$ for alamethicin-DPhPC, a value that is also very similar to the $(4.45 \pm 0.09) \times 10^{-36} \mathrm{Jm}^{2}$ published for the magainin-POPC system 
(Bouvrais, et al., 2008). In contrast to magainin, alamethicin is uncharged. Yet the $(t-s)$ values for the magainin-POPC system were obtained in a buffer at high ionic strength. It is therefore expected that the molecular interactions of alamethicin within the same monolayer and on different leaflets are comparable to those of magainin. It should be noted that fitted parameters $\lambda$ and $(t-s)$ do not change significantly using either $A_{\mathrm{Ala}}=280 \AA^{2}$ or the physical cross-section of alamethicin of $350 \AA^{2}$ instead. Finally, one of the main conclusion that can be drawn from this is that the type of pores formed by an amphipathic peptide at high concentration, i.e., barrel stave for alamethicin and toroidal for magainin (He, et al., 1996; Huang, 2006; Lee, et al., 2008; Ludtke, et al., 1996; Yang, et al., 2001), does not lead to any significant difference in the peptide-triggered softening effect.

However, melittin-induced membrane softening differs dramatically, showing a very distinct destabilization effect. As a result the fitted parameters obtained when applying Eq. (3) to the bending elasticity lowering as a function of adsorbed peptides are also quite different. Still, on may argue that the peptides cross sectional area undergoes a reduction due to the S-to-I transition which has not been taken into account. As already mentioned, the approach we used herein, although simple, is rather robust and is not very sensitive to the exact peptide area. A strong change in peptide area coverage does only compress or dilate the curve along the x-axis yet without changing the overall shape of the bending elasticity reduction or the main information obtained from the fitting procedure. Also, at low peptide concentration, the peptide can always be assumed to be in the S-state, then as peptide concentrations increase above the S-to-I transition, the peptide is going to insert gradually. This means that the peptide area coverage in Fig. 6 may become more and more overestimated above the S-to-I transition (see also error bars in Fig. 6). This would only make the differences between the alamethicin-DPhPC and the 
melittin-SOPC more dramatic. Third, the S-to-I transition can only be measured in concentrated systems (directly by OCD or indirectly by x-ray scattering). It is likely that under the conditions used for bending elasticity measurements, i.e., very low lipid concentration and low ionic strength, the critical concentration for insertion is shifted to much higher peptide concentrations because of the increased electrostatic repulsions, the latter point being discussed in some details later on. Considering these points, we decided to use a fixed cross sectional area for melittin. Taking $A_{\mathrm{Mel}}=190 \AA^{2}$ we found $\lambda=(4.47 \pm 0.45)$ $\mathrm{x} 10^{-29} \mathrm{Jm}$, which is approximately an order of magnitude smaller than what has been found for the alamethicin-DPhPC or magainin-POPC systems. Recalling that this parameter characterizes the coupling between membrane curvature and the compositional asymmetry of the peptide distribution, in other words the peptide-induced local curvature, we can conclude that membrane-bound monomeric melittin does not result in patches of strong local curvature. Furthermore, we obtained $(t-s)=(-6.54 \pm 1.31) \times 10^{-38} \mathrm{Jm}^{2}$ which is negative as already mentioned, with an absolute value relatively small compared to that of magainin-POPC (Bouvrais, et al., 2008) or alamethicin-DPhPC membranes. Under the conditions used herein, melittin is adsorbed onto SOPC bilayers with a charge parameter $v$ of about +3.1 , indicating a highly positively charged peptide. Thus, we may expect the intramonolayer interaction parameter $t$ to be positive hereby reflecting simply the mighty electrostatic repulsions that should occur between interfacial charges in a low ionic strength buffer. Assuming our aqueous solutions were containing essentially monovalent ions with [salt $] \approx 5 \mathrm{mmol} / \mathrm{L}$ (see above), the Debye-Hückel length may be estimated to be equal to $l_{D} \approx 3 \cdot 10^{-10} / \sqrt{[\text { salt }]}=42 \AA$ (Hiemenz and Rajagopalan, 1997) while the Bjerrum length for water at room temperature is $l_{B}=7 \AA$. Therefore we found $t \sim v^{2} k_{B} T \times l_{D} l_{B} \approx 10^{-37} \mathrm{Jm}^{2}$, i.e., a value that lies in the upper range of the estimations for repulsive interactions (Bouvrais, et al., 2008). More interestingly, 
a negative $(t-s)$ value implies the intermonolayer parameter $s$ is also quite strongly positive with a value about $50 \%$ higher than that for $t$. This means that the repulsions between two melittin molecules included in two different leaflets are stronger than the repulsions occurring between peptides within the same monolayer. It is worthwhile to emphasize that under the experimental conditions used herein, both interaction parameters $t$ and $s$ are positive. For this reason, the probability for some melittin molecules to self-associate in the membrane and produce a transmembrane channel-like passage should be rather small in low ionic strength buffers. Indeed, this conclusion was already obtained some time ago when analyzing time-resolved fluorescence energy transfer measurements in melittin-phosphatidylcholine systems, where a buffer containing $1 \mathrm{~mol} / \mathrm{L} \mathrm{NaCl}$ was shown to be necessary to provoke a fraction of about $10 \%$ of the adsorbed melittin to span the bilayer above the threshold of $P^{b} / L \approx 1 / 200$ (John and Jähnig, 1991) while other published works found that the transition from the $S$ (the $\alpha$-helix axis perpendicular to the local normal) to I (the $\alpha$-helix axis parallel to the local normal) state for phosphatidylcholinemelittin systems in water was between $P^{b} / L \approx 1 / 60$ and 1/40 (Chen, et al., 2003; Wu, et al., 1995).

In the following, we are going to discuss the very different softening effects found for melittin and alamethicin (or magainin) starting with high peptide area coverages. Both alamethicin and magainin produce mixtures with lipids characterized by $t-s>0$, leading to an almost constant $k_{c}^{\text {eff }}$ for high bound peptide fractions. For such high peptide concentrations, alamethicin as well as magainin are known to self-associate, forming transmembrane barrelstave or toroidal pores respectively (Bechinger, 1997; Huang, 2006). This behavior is thought to be closely related to their antibiotic actions (Zasloff, 2002). On the other hand, for monomeric melittin in low ionic strength buffer, $t-s<0$ (Fig. 6) and membrane perturbations are dominated by repulsions 
between peptides. Extrapolating the continuous curve fit of the measured bending elasticity for melittin-SOPC mixtures (Fig. 6) leads to apparent annulation of $k_{c}^{\text {eff }}$ close to $A C_{P}=0.07$ This melittin coverage corresponds to an area per peptide equal to $A_{P} / A C_{P} \approx 2700 \AA^{2}$, i.e., one single adsorbed peptide in a square with sides of $52 \AA$ and a ratio $P^{b} / L \approx 1 / 41=0.024$. At such high peptide content, melittin was also shown to self-associate across the membrane producing toroidal pores in a way similar to magainin (Yang, et al., 2001). Anyhow, these results have been obtained with very concentrated, oriented multilayer peptide-lipid systems that do not always compare well to diluted liposomes. As already mentioned in the experimental section, dilute aqueous SOPC dispersions used to prepare oriented multilayer sample showed optical clearance upon the addition of high melittin concentrations. On the contrary, such melittin-induced morphological transition remains unseen in much more concentrated lipid systems like oriented multilayer stacks. Bending elasticity measurements were done using GUVs dispersed in the buffer at a lipid concentration close to $4 \times 10^{-3} \mathrm{mg} / \mathrm{mL}$. Bilayers are therefore completely isolated and possibly subject to melittin-triggered morphological transitions. It can thus be concluded, that for $k_{c}^{\text {eff }} \approx 0$, extended bilayer structures should not exist anymore, giving way to smaller molecular organizations more or less like mixed micelles or even bicelles whose size should be controlled by other physical parameters like edge energy (Helfrich, 1974). This kind of melittininduced membrane solubilization has already been described before (Wessman, et al., 2008) and is sometimes referred to as the detergent-like action of melittin (Bechinger, 1997). It is rather interesting that this effect can be inferred from $k_{c}$ measurements obtained with GUVs.

Let us now focus on low peptide concentrations. The main biological action of melittin is its lytic action that occurs at very low peptide concentrations. It should further be remembered that its hemolytic action 

requires binding of monomeric melittin to the red blood cell membrane (Hider, et al., 1983). In the case of our environmental conditions, we found a complete lysis at a very small peptide concentration (Fig. 1), corresponding to $A C_{P} \sim 0.006$ -0.009 (arrow in Fig. 6). This is far below concentrations needed to induce the above-mentioned detergent-like action. In this concentration range, the bending elasticity of melittin-SOPC mixtures is roughly constant, whereas a sharp decrease is found for alamethicin-DPhPC (Vitkova, et al., 2006) or magaininPOPC (Bouvrais, et al., 2008). This is related to the very small $\lambda$ value in the case of melittin. Such discrepancies between the different $\lambda$ should be associated to precise molecular perturbations induced by peptide adsorption on membranes. Binding of the non-lytic peptides alamethicin and magainin leads to mobile patches of high local membrane curvature, which soften the membrane already at low concentrations where membrane thinning is still negligible. Monomeric melittin on the contrary has only a very small effect on local membrane curvature (small $\lambda$ ). This shows that although overall membrane thinning caused at low peptide concentrations by melittin is strictly comparable to that of alamethicin, the molecular perturbations in the vicinity of the absorbed peptides are profoundly different.

More speculative and more exciting is the finding of the molecular reasons that could explain why melittin is a lytic agent at very low peptide concentration while alamethicin and magainin are not. Following previous works (Bouvrais, et al., 2008; Vitkova, et al., 2006), we show here that intermonolayer interactions between peptides are important to understand how bending elasticity changes when peptides adsorb on bilayers. These molecular interactions regulate the way two peptides in the same monolayer or belonging to two different leaflets will behave. Whatever the peptide considered here, we expect the intramonolayer interaction parameter $t$ to be positive, characterizing repulsive interactions that should keep the peptides in their monolayer at the 
largest possible distance from each other. The peptides inserted in the other monolayer may be attracted $(s<0)$ or repelled $(s>0)$ by those on the other side. Clearly, an attractive behavior should promote pore formation and restore part of the local asymmetry of the bilayer when two peptides from different monolayers are pairing. This is what we observe in the case of magainin-POPC (Bouvrais, et al., 2008) and also for alamethicin-DPhPC mixtures. Contrariwise, melittin molecules are repelling each other within the same monolayer and also when they belong to different ones. This behavior should occur at quite large distances because experiments on SOPC-LUVs indicate the lysis to be complete at $P^{b} / L \approx 1 / 500-1 / 330\left(A C_{P} \sim 0.006-0.009\right.$, arrow in Fig. 6). In a regular square spacing, each peptide should be at about $150 \AA$ from the nearest ones in the same monolayer and about half this distance from the nearest peptides in the opposite monolayer. These distances are on one hand larger than the typical molecular scale. On the other hand, the distance separating nearest peptides in opposite monolayers is only twice the typical bilayer thickness. Therefore, peptide density fluctuation may result in perturbations produced by a given peptide adsorbed on a monolayer that overlap with those generated by a nearest peptide neighbor in the same monolayer or in the opposite one. Such overlapping disturbances may be enough to produce transient defects (openings) and instabilities responsible for the lytic activity similar to what has been proposed by (Bechinger, 1997). This points toward the idea that lytic and hemolytic activity might mainly be related to rather long-range peptide interactions and not intrinsically to peptide-induced local curvature effects. However, further work is clearly necessary to affirm this kind of view. Meanwhile this study reveals some elements of the subtle nature of the interactions of amphipathic peptides with membrane and show that bending elasticity measurements might be a sensitive way to distinguish between lytic and non-lytic antimicrobial peptides. 


\section{Acknowledgement}

We are grateful to J.H. Ipsen and J.C. Talbot for valuable discussions and advices. 


\section{References}

Allende, D., Simon, S. A., McIntosh, T. J., (2005). Melittin-induced bilayer leakage depends on lipid material properties: Evidence for toroidal pores. Biophys. J. 88, 1828-1837.

Allende, D., Vidal, A., Simon, S. A., McIntosh, T. J., (2003). Bilayer interfacial properties modulate the binding of amphipathic peptides. Chem. Phys. Lipids 122, 65-76.

Bechinger, B., (1997). Structure and functions of channel-forming peptides: Magainins, cecropins, melittin and alamethicin. J. Membrane Biol. 156, 197-211.

Bechinger, B., (2009). Rationalizing the membrane interactions of cationic amphipathic antimicrobial peptides by their molecular shape. Curr. Opin. Colloid Int. Sci. 14, 349-355.

Bechinger, B., (2011). Insights into the mechanisms of action of host defence peptides from biophysical and structural investigations. J. Pept. Sci. 17, 306-314.

Bechinger, B., Lohner, K., (2006). Detergent-like actions of linear amphipathic cationic antimicrobial peptides. Biochim. Biophys. Acta (BBA)-Biomembr. $1758,1529-1539$.

Blaurock, A. E., (1971). Structure of the nerve myelin membrane: Proof of the low resolution profile. J. Mol. Biol. 56, 35-52.

Bouvrais, H., Méléard, P., Pott, T., Jensen, K. J., Brask, J., Ipsen, J. H., (2008). Softening of POPC membranes by magainin. Biophys. Chem. 137, 7-12.

Bouvrais, H., Pott, T., Bagatolli, L. A., Ipsen, J. H., Méléard, P., (2010). Impact of membrane-anchored fluorescent probes on the mechanical properties of lipid bilayers. Biochim. Biophys. Acta (BBA)-Biomembr. 1798, 1333-1337.

Castano, S., Cornut, I., Büttner, K., Dasseux, J. L., Dufourcq, J., (1999). The amphipathic helix concept: length effects on ideally amphipathic $\mathrm{LiKj}(\mathrm{i}=2 \mathrm{j})$ peptides to acquire optimal hemolytic activity. Biochim. Biophys. Acta (BBA)-Biomembr. 1416, 161-175. 
Chen, F.-Y., Lee, M.-T., Huang, H. W., (2002). Sigmoidal concentration dependence of antimicrobial peptide activities: A case study on alamethicin. Biophys. J. 82, 908-914.

Chen, F.-Y., Lee, M.-T., Huang, H. W., (2003). Evidence for membrane thinning effect as the mechanism for peptide-induced pore formation. Biophys. J. 84, 3751-3758.

Dathe, M., Wieprecht, T., (1999). Structural features of helical antimicrobial peptides: their potential to modulate activity on model membranes and biological cells. Biochim. Biophys. Acta (BBA)-Biomembr. 1462, 71-87.

DeGrado, W. F., Kezdy, F. J., Kaiser, E. T., (1981). Design, synthesis, and characterization of a cytotoxic peptide with melittin-like activity. J. Am. Chem. Soc. 103, 679-681.

Dempsey, C. E., (1990). The action of melittin on membranes. Biochim. Biophys. Acta $1031,143-161$.

Dufourcq, J., Faucon, J. F., Fourche, G., Dasseux, J. L., Le Maire, M., GulikKrzywicki, T., (1986). Morphological changes of phosphatidylcholine bilayers induced by melittin: Vesicularization, fusion, discoidal particles. Biochim. Biophys. Acta 859, 33-48.

Engel, M. F. M., (2009). Membrane permeabilization by Islet Amyloid Polypeptide. Chem. Phys. Lipids 160, 1-10.

Faucon, J. F., Dufourcq, J., Lussan, C., (1979). The self-association of melittin and its binding to lipids: An intrinsic fluorescence polarization study. FEBS Lett. 102, 187-190.

Fernandez-Puente, L., Bivas, I., Mitov, M. D., Méléard, P., (1994). Temperature and chain length effects on bending elasticity of phosphatidylcholine bilayers. Europhys. Lett. 28, 181.

Franks, N. P., Lieb, W. R., (1979). The structure of lipid bilayers and the effects of general anesthetics: An x-ray and neutron diffraction study. J. Mol. Biol. 133, 469-500.

Habermann, E., (1972). Bee and wasp venoms. Science 177, 314-322. 
He, K., Ludtke, S. J., Worcester, D. L., Huang, H. W., (1996). Neutron scattering in the plane of membranes: structure of alamethicin pores. Biophys. J. 70, 2659-2666.

Helfrich, W., (1974). The size of bilayer vesicles generated by sonication. Phys. Lett. A 50, 115-116.

Heller, W. T., He, K., Ludtke, S. J., Harroun, T. A., Huang, H. W., (1997). Effect of changing the size of lipid headgroup on peptide insertion into membranes. Biophys. J. 73, 239-244.

Hider, R. C., Khader, F., Tatham, A. S., (1983). Lytic activity of monomeric and oligomeric melittin. Biochim. Biophys. Acta (BBA)-Biomembr. 728, 206-214.

Hiemenz, P. C., Rajagopalan, R., (1997). Principles of Colloid and Surface Chemistry, revised and expanded. Marcel Dekker, Inc., New York, Basel, Hong Kong

Huang, H. W., (2006). Molecular mechanism of antimicrobial peptides: The origin of cooperativity. Biochim. Biophys. Acta (BBA)-Biomembr. 1758, 1292-1302.

Huang, H. W., Chen, F.-Y., Lee, M.-T., (2004). Molecular Mechanism of PeptideInduced Pores in Membranes. Phys. Rev. Lett. 92, 198304.

Jacobs, R. E., White, S. H., (1989). The nature of the hydrophobic binding of small peptides at the bilayer interface: Implications for the insertion of transbilayer helices. Biochemistry 28, 3421-3437.

John, E., Jähnig, F., (1991). Aggregation state of melittin in lipid vesicle membranes. Biophys. J. 60, 319-328.

Kagan, B. L., Jang, H., Capone, R., Teran Arce, F., Ramachandran, S., Lal, R., Nussinov, R., (2012). Antimicrobial Properties of Amyloid Peptides. Mol. Pharmaceutics 9, 708-717.

Kučerka, N., Nieh, M.-P., Katsaras, J., (2011). Fluid phase lipid areas and bilayer thicknesses of commonly used phosphatidylcholines as a function of temperature. Biochim. Biophys. Acta (BBA)-Biomembr. 1808, 2761-2771. 
Kuchinka, E., Seelig, J., (1989). Interaction of melittin with phosphatidylcholine membranes. Binding isotherm and lipid head-group conformation. Biochemistry 28, 4216-4221.

Lee, M.-T., Chen, F.-Y., Huang, H. W., (2004). Energetics of pore formation induced by membrane active peptides. Biochemistry 43, 3590-3599.

Lee, M.-T., Hung, W.-C., Chen, F.-Y., Huang, H. W., (2005). Many-body effect of antimicrobial peptides: On the correlation between lipid's spontaneous curvature and pore formation. Biophys. J. 89, 4006-4016.

Lee, M.-T., Hung, W.-C., Chen, F.-Y., Huang, H. W., (2008). Mechanism and kinetics of pore formation in membranes by water-soluble amphipathic peptides. Proc. Natl. Acad. Sci. USA 105, 5087-5092.

Leibler, S., (1986). Curvature instability in membranes. J. Physique 47, 507-516.

Leitgeb, B., Szekeres, A., Manczinger, L., Vágvölgyi, C., Kredics, L., (2007). The History of alamethicin: A review of the most extensively studied peptaibol. Chemistry \& Biodiversity 4, 1027-1051.

Li, C., Salditt, T., (2006). Structure of magainin and alamethicin in model membranes studied by x-ray reflectivity. Biophys. J. 91, 3285-3300.

Ludtke, S. J., He, K., Heller, W. T., Harroun, T. A., Yang, L., Huang, H. W., (1996). Membrane pores induced by magainin. Biochemistry 35, 13723-13728.

Mahalka, A. K., Kinnunen, P. K. J., (2009). Binding of amphipathic $\alpha$-helical antimicrobial peptides to lipid membranes: Lessons from temporins B and L. Biochim. Biophys. Acta (BBA)-Biomembr. 1788, 1600-1609.

Matsuzaki, K., (1998). Magainins as paradigm for the mode of action of pore forming polypeptides. Biochim. Biophys. Acta (BBA)-Biomembr. 1376, 391-400.

Matsuzaki, K., Yoneyama, S., Miyajima, K., (1997). Pore formation and translocation of melittin. Biophys. J. 73, 831-838.

McIntosh, T. J., Simon, S. A., (1986). Area per molecule and distribution of water in fully hydrated dilauroylphosphatidylethanolamine bilayers. Biochemistry 25, 4948-4952. 
Méléard, P., Bagatolli, L. A., Pott, T., Nejat, D. (2009) Chapter 9 - Giant unilamellar vesicle electroformation: From lipid mixtures to native membranes under physiological conditions Methods in Enzymology, vol Volume 465. Academic Press, pp 161-176

Méléard, P., Gerbeaud, C., Bardusco, P., Jeandaine, N., Mitov, M. D., FernandezPuente, L., (1998). Mechanical properties of model membranes studied from shape transformations of giant vesicles. Biochimie 80, 401-413.

Méléard, P., Gerbeaud, C., Pott, T., Fernandez-Puente, L., Bivas, I., Mitov, M. D., Dufourcq, J., Bothorel, P., (1997). Bending elasticities of model membranes. Influences of temperature and cholesterol content. Biophys. J. 72, 2616-2629.

Méléard, P., Pott, T., Bouvrais, H., Ipsen, J. H., (2011). Advantages of statistical analysis of giant vesicle flickering for bending elasticity measurements. Eur. Phys. J. E 34, 1-14.

Mitkova, D., Marukovich, N., Ermakov, Y. A., Vitkova, V., (2014). Bending rigidity of phosphatidylserine-containing lipid bilayers in acidic aqueous solutions. Colloid Surface A,

Nagle, J. F., Katsaras, J., (1999). Absence of a vestigial vapor pressure paradox. Phys. Rev. E 59, 7018-7024.

Nagle, J. F., Zhang, R., Tristram-Nagle, S., Sun, W., Petrache, H. I., Suter, R. M., (1996). X-ray structure determination of fully hydrated L $\alpha$ phase dipalmitoylphosphatidylcholine bilayers. Biophys. J. 70, 1419-1431.

Ollivon, M., Eidelman, O., Blumenthal, R., Walter, A., (1988). Micelle-vesicle transition of egg phoshatidylcholine and octyl glucoside. Biochemistry 27, 1695-1703.

Oršolić, N., (2012). Bee venom in cancer therapy. Cancer Metast. Rev. 31, 173-194.

Pabst, G., Danner, S., Podgornik, R., Katsaras, J., (2007). Entropy-Driven Softening of Fluid Lipid Bilayers by Alamethicin. Langmuir 23, 11705-11711.

Pan, J., Tieleman, D. P., Nagle, J. F., Kučerka, N., Tristram-Nagle, S., (2009). Alamethicin in lipid bilayers: Combined use of X-ray scattering and MD simulations. Biochim. Biophys. Acta (BBA)-Biomembr. 1788, 1387-1397. 
Paternostre, M.-T., Roux, M., Rigaud, J.-L., (1988). Mechanisms of membrane protein insertion into liposomes during reconstruction procedures involving the use of Detergents. 1. Solubilization of large unilamellar liposomes (prepared by reverse-phase evaporation) by triton X-100, octyl glucoside, and sodium cholate. Biochemistry 27, 2668-2677.

Petrov, A. G., Bivas, I., (1984). Elastic and flexoelectric aspects of out-of-plane fluctuations in biological and model membranes. Prog. Surf. Sci. 16, 389.

Pincet, F., Cribier, S., Perez, E., (1999). Bilayers of neutral lipids bear a small but significant charge. Eur. Biophys. J. 11, 127-130.

Pott, T., Bouvrais, H., Méléard, P., (2008). Giant unilamellar vesicle formation under physiologically relevant conditions. Chem. Phys. Lipids 154, 115-119.

Pott, T., Paternostre, M.-T., Dufourc, E. J., (1998). A comparative study of the action of melittin on sphingomyelin and phosphatidylcholine bilayers. Eur. Biophys. J. 27, 237-245.

Quay, S. C., Condie, C. C., (1983). Conformational studies of aqueous melittin: Thermodynamic parameters of the monomer-tetramer self-association reaction. Biochemistry 22, 695-700.

Raghuraman, H., Chattopadhyay, A., (2007). Melittin: A membrane-active peptide with diverse functions. Bioscience Rep. 27, 189-223.

Rand, R. P., Fuller, N., Parsegian, V. A., Rau, D. C., (1988). Variation in hydration forces between neutral phospholipid bilayers: evidence for hydration attraction. Biochemistry 27, 7711-7722.

Rex, S., Schwarz, G., (1998). Quantitative studies on the melittin-induced leakage mechanism of lipid vesicles. Biochemistry 37, 2336-2345.

Schwarz, G., Beschiaschvili, G., (1989). Thermodynamic and kinetic studies on the association of melittin with phospholipids. Biochim. Biophys. Acta 979, 82.

Schwarz, G., Stankowski, S., Rizzo, V., (1986). Thermodynamic analysis of incorporation and aggregation in a membrane: Application to the poreforming peptide alamethicin. Biochim. Biophys. Acta (BBA)-Biomembr. 861, 141-151. 
Smith, R., Separovic, F., Milne, T. J., Whittaker, A., Bennett, F. M., Cornell, B. A., Makriyannis, A., (1994). Structure and orientation of the pore-forming peptide, melittin, in lipid bilayers. J. Mol. Biol. 241, 456-466.

Szleifer, I., Kramer, D., Ben-Shaul, A., Gelbart, W. M., Safran, S. A., (1990). Molecular theory of curvature elasticity in surfactant films. J. Chem. Phys. $92,6800-6817$.

Talbot, J.-C., Lalanne, J., Faucon, J.-F., Dufourcq, J., (1982). Effect of the state of association of melittin and phospholipids on their reciprocal binding. Biochim. Biophys. Acta (BBA)-Biomembr. 689, 106-112.

Talbot, J. C., Dufourcq, J., De Bony, J., Faucon, J. F., Lussan, C., (1979). Conformational change and self-association of monomeric melittin. FEBS Lett. 102, 191-193.

Torrens, F., Castellano, G., Campos, A., Abad, C., (2007). Negatively cooperative binding of melittin to neutral phospholipid vesicles. J. Mol. Structure 834-836, 216-228.

Tosteson, M. T., Holmes, S. J., Razin, M., Tosteson, D. C., (1985). Melittin lysis of red cells. J. Membrane Biol. 87, 35-44.

Tristram-Nagle, S., Petrache, H. I., Nagle, J. F., (1998). Structure and Interactions of Fully Hydrated Dioleoylphosphatidylcholine Bilayers. Biophys. J. 75, 917-925.

Vitkova, V., Méléard, P., Pott, T., Bivas, I., (2006). Alamethicin influence on the membrane bending elasticity. Eur. Biophys. J. 35, 281-286.

Wessman, P., Strömstedt, A. A., Malmsten, M., Edwards, K., (2008). Melittinlipid bilayer interactions and the role of cholesterol. Biophys. J. 95, 4324-4336.

Wiener, M. C., White, S. H., (1991). Transbilayer distribution of bromine in fluid bilayers containing a specifically brominated analogue of dioleoylphosphatidylcholine. Biochemistry 30, 6997-7008.

Wieprecht, T., Beyermann, M., Seelig, J., (1999). Binding of antibacterial magainin peptides to electrically neutral membranes: Thermodynamics and structure. Biochemistry 38, 10377-10387. 
Wu, Y., He, K., Ludtke, S. J., Huang, H. W., (1995). X-ray diffraction study of lipid bilayer membranes interacting with amphiphilic helical peptides: Diphytanoyl phosphatidylcholine with alamethicine at low concentrations. Biophys. J. 68, 2361-2369.

Yang, L., Harroun, T. A., Weiss, T. M., Ding, L., Huang, H. W., (2001). Barrelstave model or toroidal model? A case study on melittin pores. Biophys. J. 81, 1475-1485.

Zasloff, M., (2002). Antimicrobial peptides of multicellular organisms. Nature 415, 389-395. 

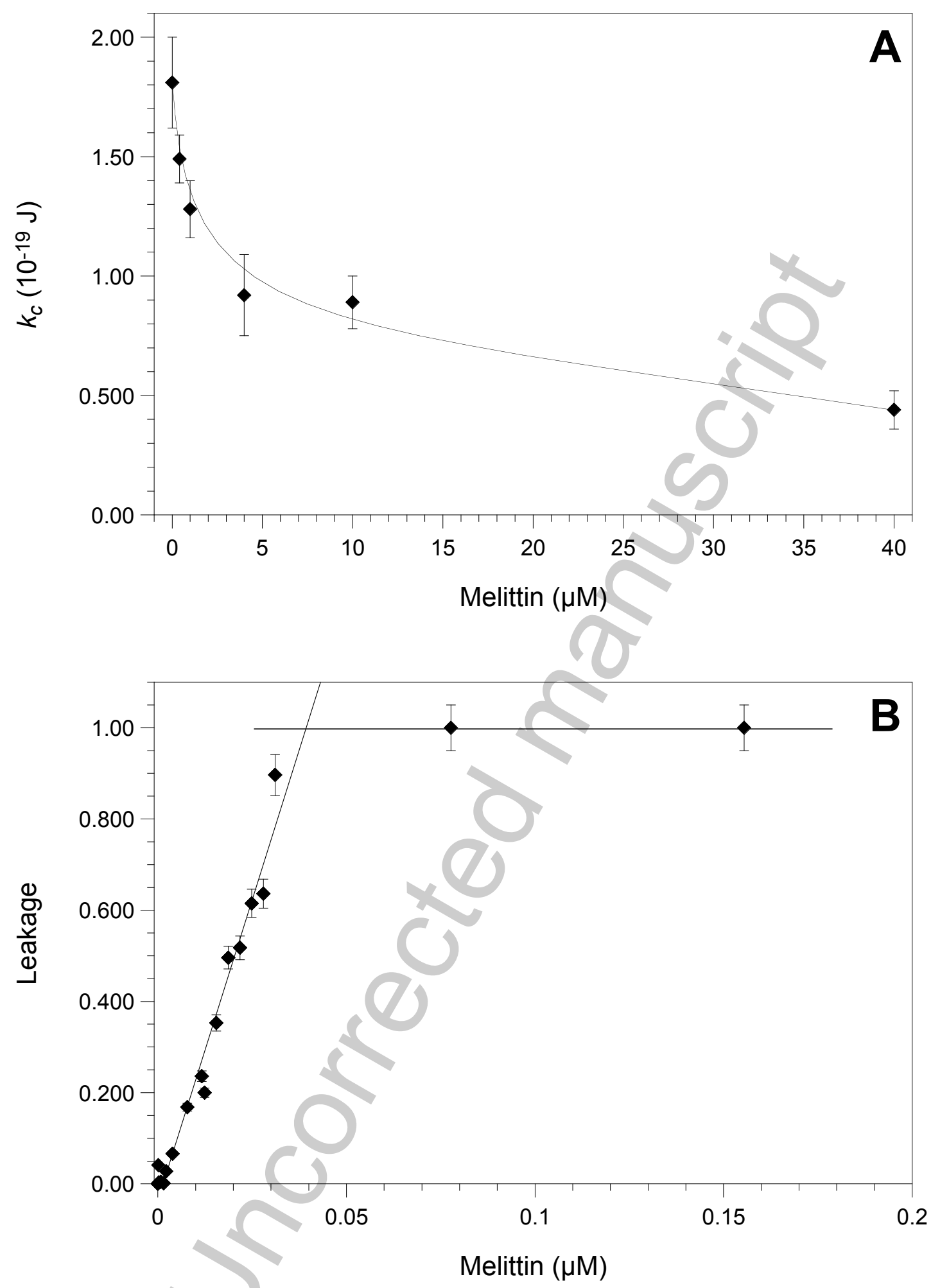

Fig. 1: (A) Experimental evolution of the bending elasticity of SOPC membranes as a function of total melittin concentration at a fixed lipid concentration of about $8 \mu \mathrm{mol} / \mathrm{L}$. (B) Fraction of lysed SOPC LUVs as a function of total melittin concentration at a fixed lipid concentration of about $16 \mu \mathrm{mol} / \mathrm{L}$. Lines are drawn as eye guidelines. 


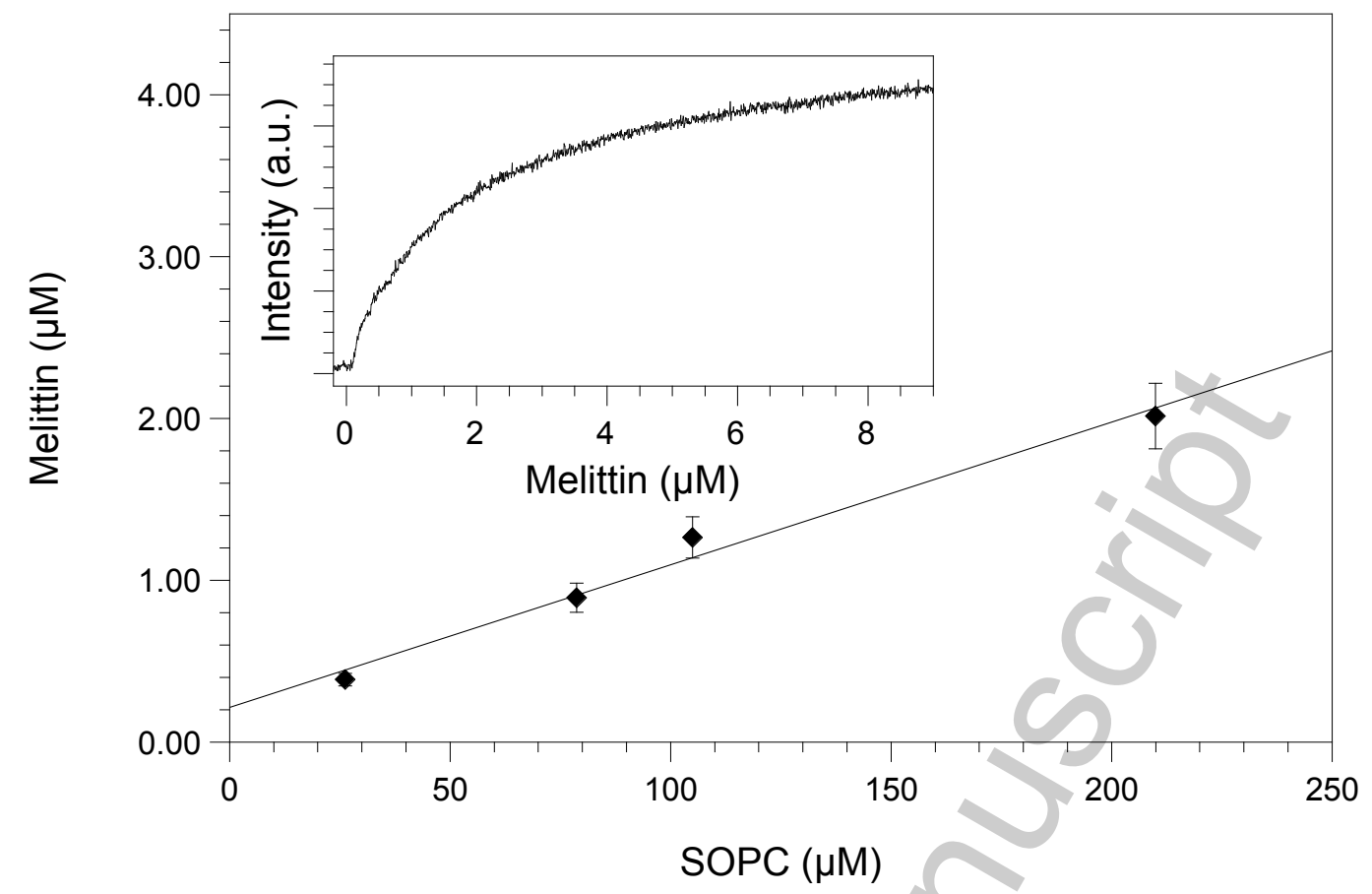

Fig. 2: Experimental determination of the total amount of melittin, $P$, needed to obtain a given unbounded peptide $P f$ at different lipid concentration $L$ : in this case, the slope gives directly the bound peptide to lipid ratio, $P b / L=114$ and the intercept the free peptide, $P^{f}=0.22 \mu \mathrm{mol} / \mathrm{L}$ (see text for details). Insert: Evolution of the fluorescence intensity at a SOPC concentration, $L$, equal to $105 \mu \mathrm{mol} / \mathrm{L}$, as a function of total melittin concentration, $P$. 


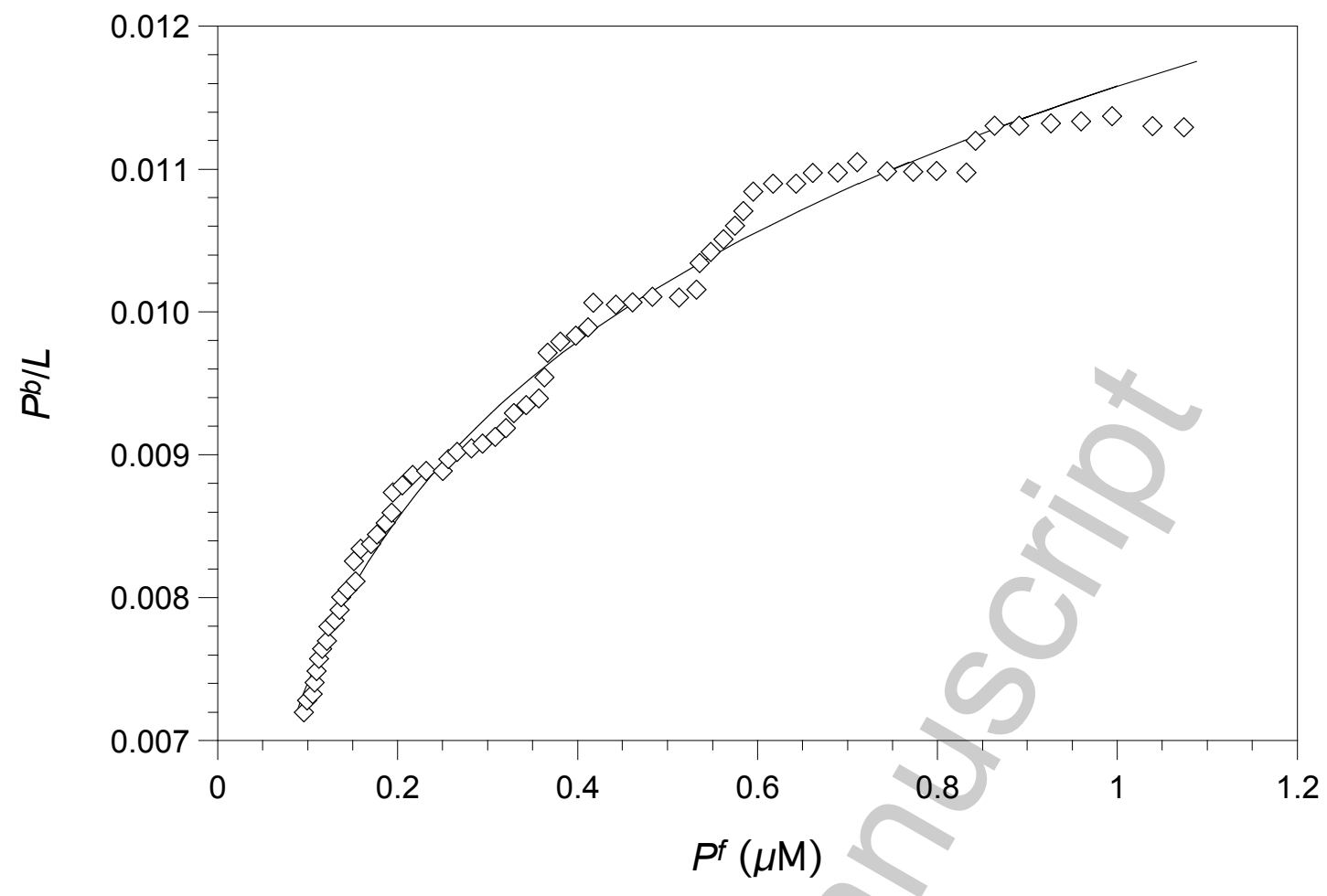

Fig. 3: Bound peptide per lipid $P^{b} / L$ as a function of the free peptide concentration $P^{f}$ as obtained by FRET experiments (open squares) and the corresponding solid curve obtained using Eq.(2) and the fitted parameters $K_{P}=4.7 \times 10^{6} \mathrm{~L} / \mathrm{mol}, v=3.1$ and $\beta=97$ (see text). 

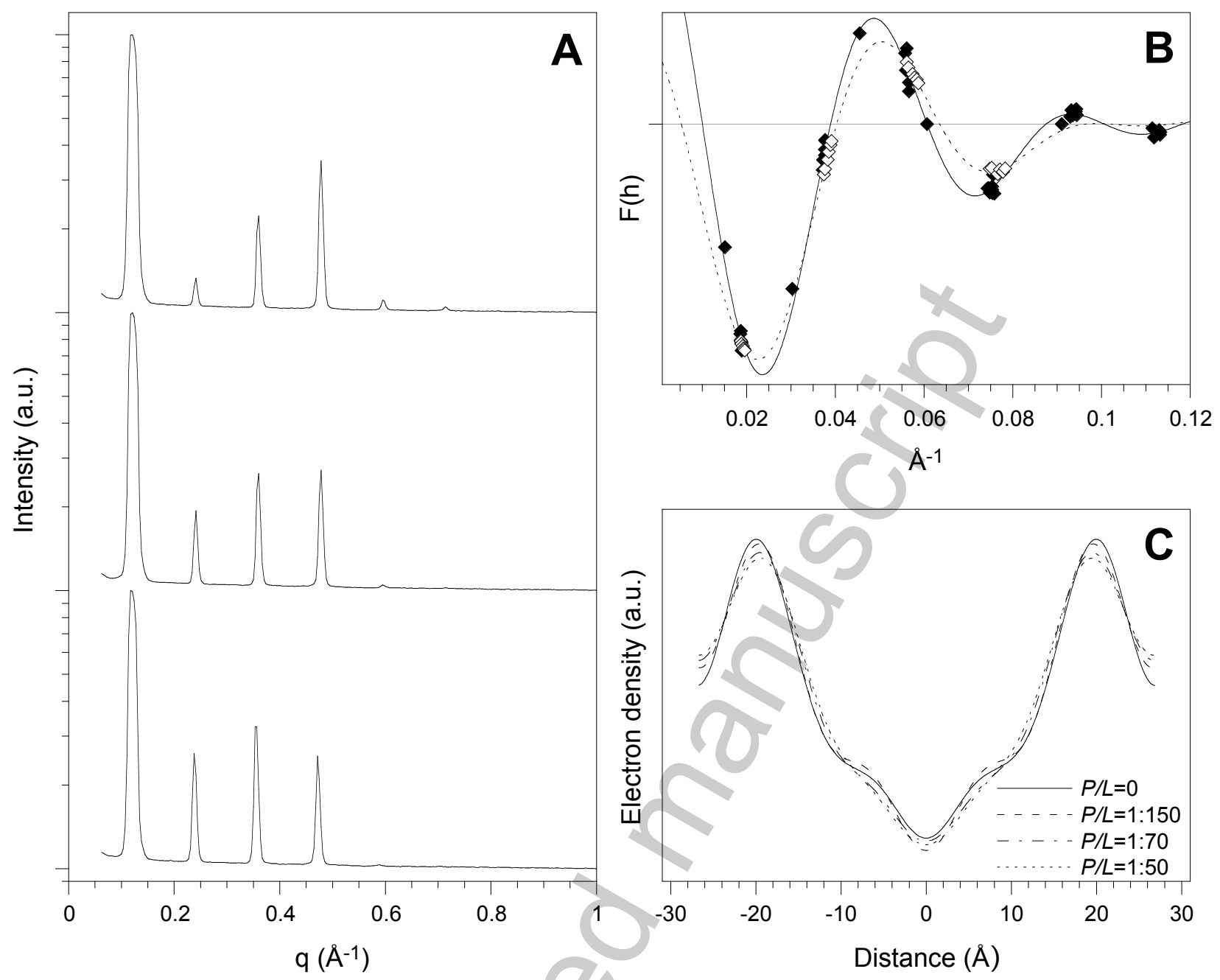

Fig. 4: (A) Typical diffraction patterns of pure SOPC at 100\% (bottom), $92 \%$ (middle) and $84 \%$ (top) relative humidity. Up to 6 orders are observed. (B) Phasing diagram for pure SOPC $(\diamond)$ and the melittin-SOPC mixture at $P / L=1: 70(\diamond)$. (C) Selected electron density profiles obtained for the melittin-SOPC system at $100 \%$ relative humidity and $P / L=0$, $1: 150,1: 70$ and $1: 50$. 


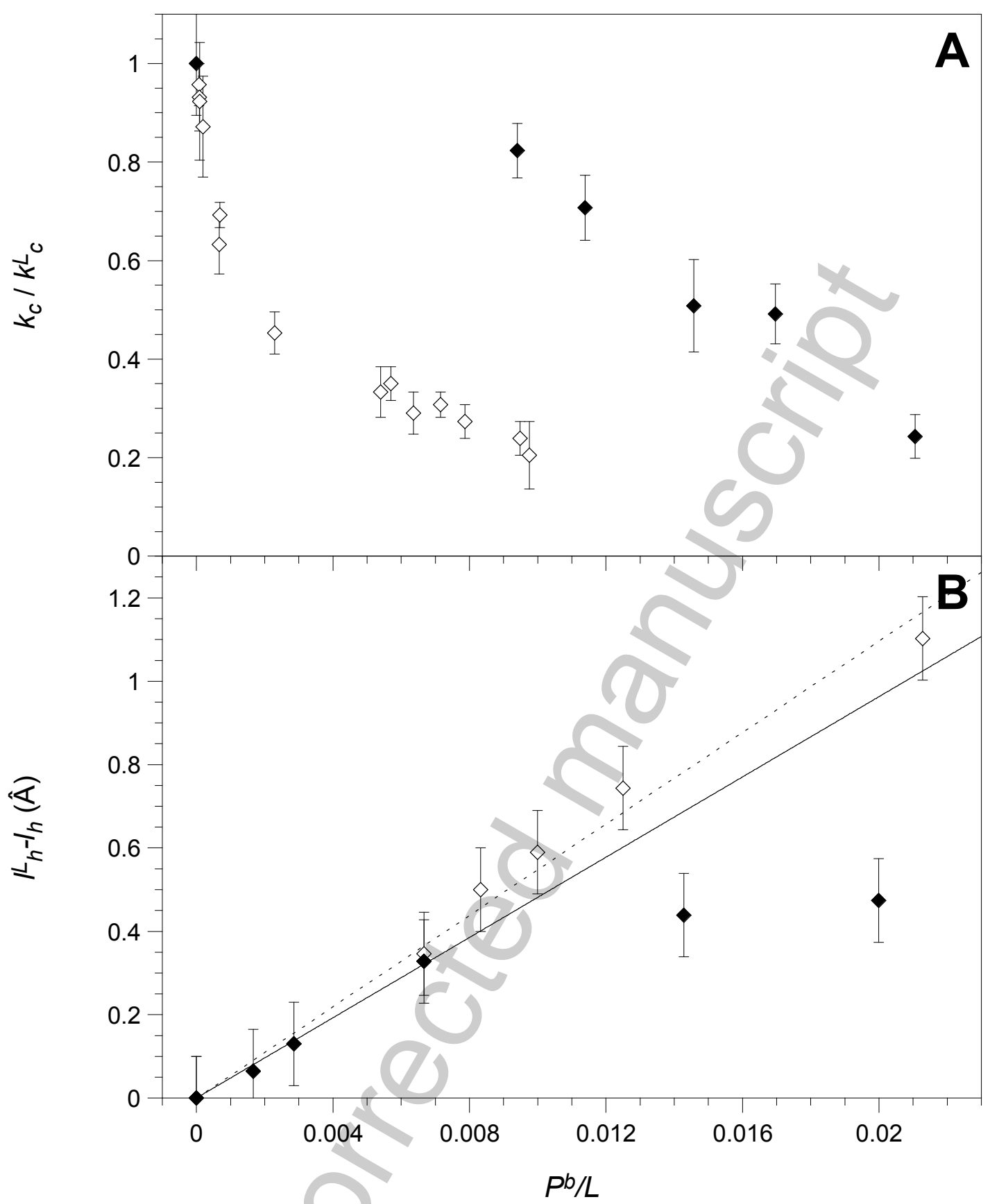

Fig. 5: Comparison of the SOPC-melittin system (filled symbols and solid lines) with the published DPhPC-alamethicin (open symbols and dashed lines) system. (A) Peptideinduced reduction in bending elasticity, $k_{c}$, with respect to pure lipid bending elasticity $k_{c}^{L}$ as a function of $P^{b} / L$. Data for the DPhPC-alamethicin system was taken from (Vitkova, et al., 2006). (B) Peptide-induced decrease in monolayer thickness and the corresponding fitted decrease (solid and dashed lines) as determined from X-ray measurements. Data for the DPhPC-alamethicin systems was taken from Fig. 9 in ( $\mathrm{Wu}$, et al., 1995). 


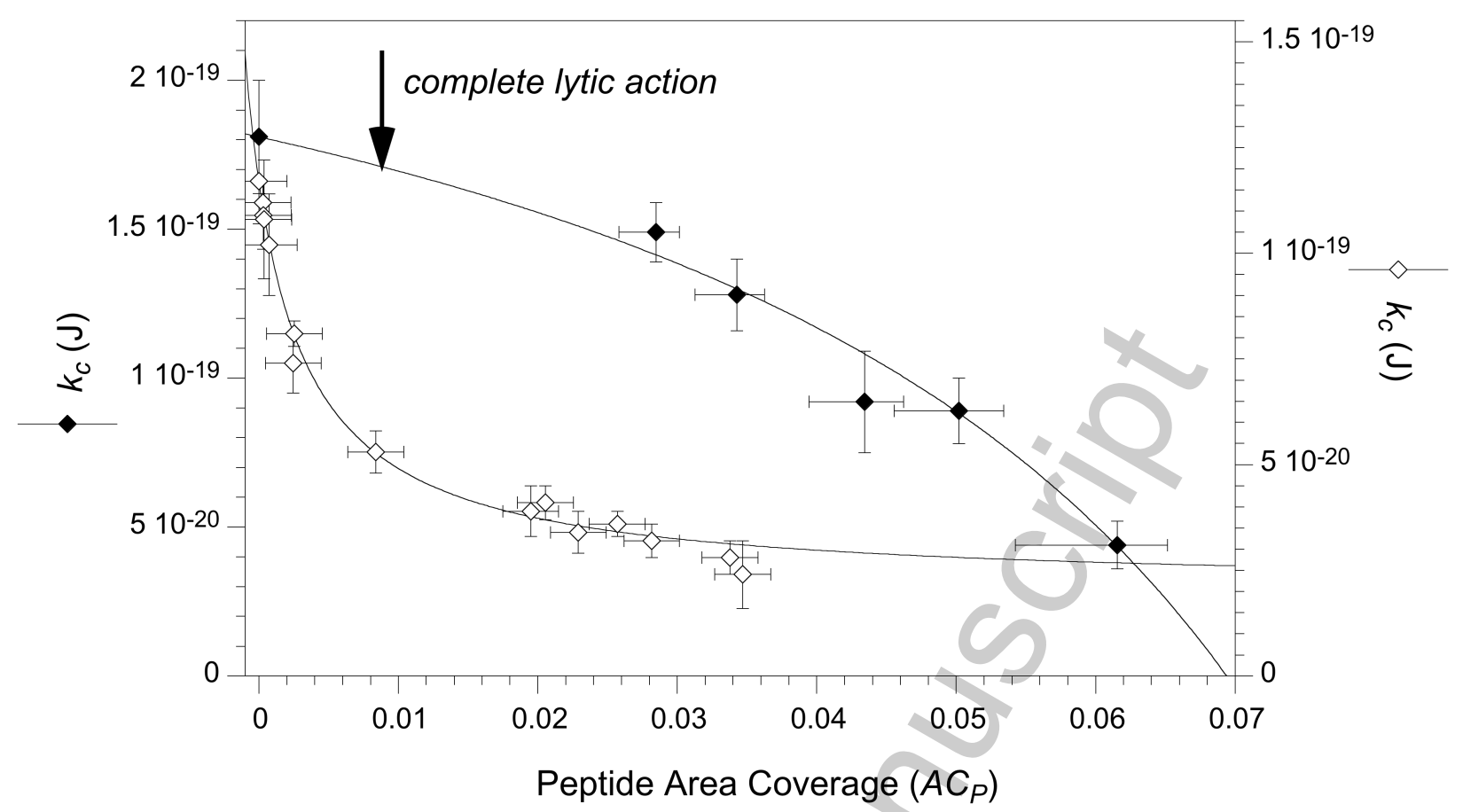

Fig. 6 : Bending elasticity of melittin-SOPC (filled symbols) and alamethicin-DPhPC (open symbols, data from (Vitkova, et al., 2006)) systems as a function of peptide area coverage $\left(A C_{P}\right.$, see text). The data can be fitted (continuous lines) following the approach developed in the literature (Bouvrais, et al., 2008). Taking $A_{p}=190 \AA^{2}$ as determined from X-ray data for melittin-SOPC system results in $\lambda=(4.47 \pm 0.45) \times 10^{-29} \mathrm{Jm}$ and $(t-s)=(-6.54 \pm 1.31)$ x10-38 $\mathrm{Jm}^{2}$. Using the value of $A_{p}=400 \AA^{2}$ leads to $\lambda=(4.47 \pm 0.45) \times 10^{-29} \mathrm{Jm}$ and $(t-$ $s)=(-7.38 \pm 1.31) \times 10^{-38} \mathrm{Jm}^{2}$. Alamethicin-DPhPC system (using $A_{p}=280 \AA^{2}$ as determined from X-ray data $\left(\mathrm{Wu}\right.$ et al, 1995)) results in $\lambda=(2.53 \times 10 \pm 0.16)^{-28} \mathrm{Jm}$ and $(t-s)=(2.65 \pm 0.40)$ $\mathrm{x} 10^{-36} \mathrm{Jm}^{2}$. Using the value of $A_{p}=350 \AA^{2}$ instead give the same results. 